Int. J. Dev. Biol. 55: 383-388

doi: $10.1387 / \mathrm{ijdb} .103216 \mathrm{dr}$

\title{
From the discovery of Vascular Endothelial Growth Factor to the introduction of Avastin in clinical trials - an interview with Napoleone Ferrara
}

\author{
DOMENICO RIBATTI* \\ Department of Human Anatomy and Histology, University of Bari Medical School, Bari, Italy
}

\begin{abstract}
Napoleone Ferrara and his colleagues at Genentech were the first to isolate and clone vascular endothelial growth factor (VEGF) in 1989. His laboratory has investigated many aspects of VEGF biochemistry and molecular biology. In 1993, Ferrara reported that inhibition of VEGF-induced angiogenesis by specific monoclonal antibodies resulted in dramatic suppression of the growth of a variety of tumors in vivo. These findings provided an important evidence that inhibition of angiogenesis may suppress tumor growth and blocking VEGF action could have therapeutic value for a variety of malignancies. A further development was the design in a rational fashion in 1997 of a humanized anti-VEGF monoclonal antibody (Avastin), now in clinical trials as a treatment for several solid tumors and also outside of cancer, in the treatment of age-related macular degeneration (AMD). Ferrara's work is revolutionizing quality of life for many of the estimated 1.2 million individuals in the US who have wet AMD. Upwards of a million AMD patients worldwide have already received anti-VEGF antibody therapy.
\end{abstract}

KEY WORDS: Interview, avastin, macular degeneration, tumor growth, vascular endothelial growth factor.

Napoleone Ferrara (Fig. 1) and his colleagues at Genentech (Fig. 2) were the first to isolate and clone vascular endothelial growth factor (VEGF) (Ferrara and Henzel, 1989). Ferrara and Henzel reported the isolation of a diffusible endothelial cell-specific mitogen from conditioned medium by bovine pituitary follicular cells, which they named VEGF to reflect the restricted target cell specificity of this molecule. $\mathrm{NH}_{2}$-terminal amino acid sequencing of purified VEGF proved that this protein was distinct from the known endothelial cell mitogens such as acidic and basic fibroblast growth factor (aFGF and bFGF) and indeed did not match any known protein in available databases (Ferrara and Henzel, 1989). By the end of 1989, Ferrara reported the isolation of cDNA clones for bovine VEGF $_{164}$ and three human VEGF isoforms: VEGF ${ }_{121}, V$ VGF $_{165}$ and VEGF $_{189}$ (Leung et al., 1989). Subsequent studies indicated that these isoforms had markedly different properties. VEGF ${ }_{121}$, which lacked heparin-binding, was highly diffusible, whereas VEGF ${ }_{189}$, a highly basic and heparin-binding protein, was almost completely sequestered in the extracellular matrix; VEGF VE5 $_{165}$ had intermediate properties (Houck et al., 1991). Moreover, some proteases, such as plasmin, were found to cleave heparin-binding heparin isoforms in the $\mathrm{COOH}$ terminus generating a non-heparin-binding diffusible fragments (Houck et al., 1992).
Ferrara's laboratory has investigated many aspects of VEGF biochemistry and molecular biology including: the identification and characterization of its receptors Flt-1 and Flk-1/KDR; regulation of VEGF by alternative RNA splicing and by extracellular proteolytic mechanisms; structure/function studies on the factor and its receptors, and elucidation of its role in angiogenesis in bone and reproductive system.

Over the years, five VEGF-related genes have been identified (VEGF-A, VEGF-B, VEGF-C, VEGF-D, and VEGF-E). There are five characterized VEGF-A isoforms of $121,145,165,189$, and 206 amino acids in mammals, generated by alternative splicing of the mRNA from a single gene comprising eight exons. They display differential interactions with related receptor tyrosine kinases VEGFR-1/FIt-1, VEGFR-2/FIk-1, VEGFR-3/FIt-4, and neuropilin-1 and -2 (NRP-1 and NRP-2). As a result of the receptor activation and subsequent signal transduction, VEGF-targeted cells may

Abbreviations used in this paper: AMD, age-related macular degeneration; EG-VEGF, endocrine gland-derived VEGF; HGF, hepatocyte growth factor; HIF, hypoxia inducible factor; NRP, neuropilin; PlGF, placental growth factor; VEGF, vascular endothelial growth factor.

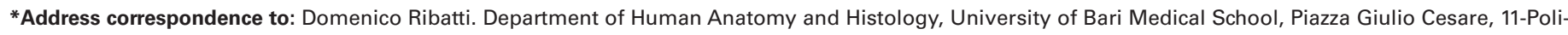
clinico. I-70124 Bari, Italy. Fax: +39-080-5478310. e-mail: ribatti@anatomia.uniba.it.
} 
proliferate, migrate or alter gene expression, e.g. of matrix metalloproteinases or cytokines.

VEGFR-1 and VEGFR-2 are restricted largely to vascular endothelium in their expression, accounting for the specificity of action of this growth factor family. In 1992 in a collaborative study between Ferrara's laboratory and Lewis Williams's group at the University of California at San Francisco, VEGFR-1 was shown to be an high-affinity VEGF receptor (de Vries et al., 1992). Ferrara also demonstrated that VEGFR-1 expression is up-regulated by hypoxia via a hypoxia inducible factor (HIF)-1-dependent mechanism (Gerber et al., 1997) and that VEGFR-1 binds not only VEGF-A, but also placental growth factor (PIGF) (Park et al., 1994).

Ferrara initially proposed that VEGFR-1 may be not primarily a receptor transmitting a mitogenic signal, but rather a "decoy" receptor, able to regulate in a negative fashion the activity of VEGF on the vascular endothelium, by sequestering and rendering this factor less available to VEGFR-2 (Park et al., 1994). Thus, the observed potentiation of the action of VEGF by PIGF could be explained, at least in part, by displacement of VEGF from VEGFR-1 binding (Park et al., 1994).

In 1996, Ferrara's laboratory (Ferrara et al., 1996) and a collaborative effort between Peter Carmeliet in Leuven, Werner Risau in Martinsried and Andras Nagy in Toronto (Carmeliet et al., 1996) demonstrated an essential role of VEGF in embryonic vasculogenesis and angiogenesis in the mouse. Inactivation of a single VEGF allele resulted in embryonic lethality between day 11 and 12 . The VEGF+/- embryos exhibited a number of developmental anomalies. The forebrain region appeared significantly underdeveloped. In the heart, the outflow region was grossly malformed; the dorsal aortas were rudimentary, and the thickness of the ventricular wall was markedly decreased. The yolk sac revealed a substantially reduced number of nucleated red blood cells within the blood islands, indicating that VEGF regulated both vasculogenesis and hematopoiesis. Also, the vitelline veins failed to fuse within the vascular plexus of the yolk sac. Significant defects in the vasculature of other tissues, including placenta and nervous system, was evidenced. For example, in the nervous system of heterozygous embryos at day 10.5, vascular elements could be demonstrated in the mesenchyme, but not in neuropeithelium and the failure of blood vessels ingrowth was accompanied by apoptosis and disorganization of neuroepithelial cells.

In 2001, Ferrara identified an endocrine gland-derived VEGF (EG-VEGF) as a novel human endothelial mitogen, through a bioassay assessing the ability of a library of purified human secreted proteins to promote the growth of primary adrenal cortex capillary endothelial cells (Le Couter et al., 2001). EG-VEGF is not structurally related to VEGF, but belongs to a unique gene family having distant homology to Dickoff, an inhibitor of Wnt signaling (Le Couter et al., 2002). Whereas VEGF mRNA is strongly expressed in early stage corpus luteum, coincident with the initially development of a capillary plexus, its expression is markedly reduced by midluteal phase. In contrast, EG-VEGF starts being expressed later than VEGF, but persists throughout mid- and -early late luteal phase, suggesting that EG-VEGF may be important for the persistence and adequacy of luteal function (Ferrara et al., 2003).

This indicates that other angiogenic factors are also likely to have organ-specific angiogenic effects. The ability of certain tumors to escape anti-VEGF strategies might be due, at least in part, to the expression of such molecules. In this context, initial evidence

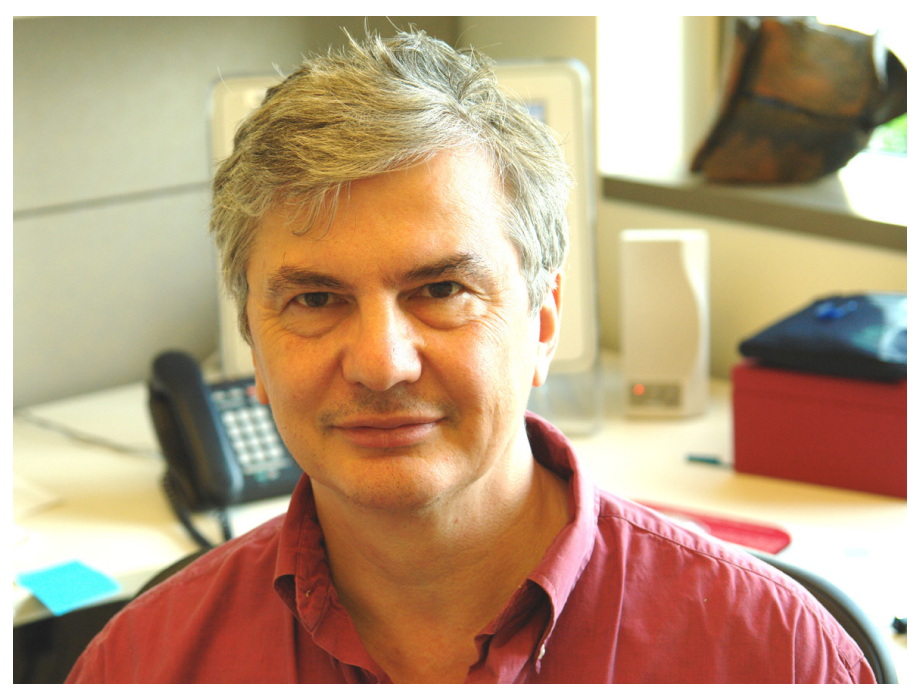

Fig. 1. A recent photo of Napoleone Ferrara in his office at the Genentech office in San Francisco, California.

indicates that VEGF and EG-VEGF are co-expressed by adrenal carcinomas, raising the possibility that a complete inhibition of angiogenesis in these tumors might require blocking both VEGF and EG-VEGF signaling pathways (Le Couter et al., 2002).

The idea developed by Ferrara of an organ-specific regulation of angiogenesis has been ascribed to genetic predisposition and "microenvironmental" influences (Cleaver and Melton, 2003). For instance, the vasculature of liver, spleen and bone marrow sinusoids is highly permeable because vessels are lined by discontinuous endothelial cells. Conversely, endothelial cells in the brain and retinal capillaries present many tight-junctions that contribute to blood-tissue barrier. Continuous endothelial cell capillaries are also found in the bone tissue, skeletal muscles, myocardium, testes and ovaries. Endothelial cells in endocrine glands and kidney are fenestrated and fenestration in the capillary endothelium seems to depend on VEGF secretion (Esser et al. 1998).

Endothelial cells release in a paracrine fashion and express to the cell surface many signaling molecules that can affect the destiny of developing tissue cells intimately associated to them. The emerging scenario is that of a general developmental model whereby cross-talk between endothelial and tissue cells would be responsible for a series of sequential inductive and differentiating events. It has been speculated that endothelial cell-tissue interactions may "offer the opportunity to control organ development and growth systematically, rather then individually for each organ" (Lammert et al. 2003). Further investigations should be addressed to understand if, upon adequate stimulation, the endothelium can be instructed to produce a series of mitogenic/survival factors that can protect parenchymal cells from injury and initiate regeneration. In the liver, for instance, the VEGF-driven paracrine supply of hepatocyte growth factor (HGF) by sinusoid endothelial cells represents a promising model for hepatocyte rescue and survival after toxic events (LeCouter et al. 2003). Indeed, HGF induction by VEGF or VEGFR-1 agonists may form the basis of a future therapeutic scheme aimed toward protection of liver parenchyma in at least some liver disorders.

Ferrara contributed to the study of the role of VEGF in the development of pancreas (Lammert et al., 2003). Deletion of VEGF 
in the mouse pancreas reveals that endocrine cells signal back to the adjacent endothelial cells to induce the formation of a dense network of fenestrated capillaries in islets. Moreover, glucose tolerance tests reveal that the VEGF-induced capillary network is not strictly required for blood glucose control but is essential for fine tuning blood glucose regulation (Lammert et al., 2003).

Ferrara and collaborators demonstrated that VEGF mRNA is expressed by hypertrophic chondrocytes in the epiphyseal growth plate, suggesting that a VEGF gradient is needed for directional growth and cartilage invasion by metaphyseal blood vessels (Gerber et al., 1999). Following VEGF blockade with a soluble VEGFR-1 chimeric protein or an anti-VEGF monoclonal antibody, blood vessel invasion is almost completely suppressed, concomitant with impaired trabecular bone formation, in mice and primates (Gerber et al., 1999). Although proliferation, differentiation and maturation of chondrocytes were apparently normal, resorption of hypertrophic chondrocytes was inhibited, resulting in a marked expansion of the hypertrophic chondrocyte zone. These findings indicate that VEGF-dependent blood vessel invasion is essential for coupling cartilage resorption with bone formation. Following VEGF inactivation, hypertrophic chondrocytes fail to undergo apoptotic cell death and cessation of the anti-VEGF treatment is followed by capillary invasion, restoration of bone growth and normalization of the growth plate architecture.

Administration of VEGF inhibitors suppresses luteal angiogenesis in a rat model of hormonally induced ovulation (Ferrara et al., 1998). This effect was associated with inhibition of corpus luteum development and progesterone release. Also, failure of maturation of the endometrium was observed, probably reflecting suppression of ovarian steroid production plus a direct inhibition of locally produced VEGF. Areas of ischemic necrosis were demonstrated in the corpus luteum of treated animals. However, no effects on the pre-existing ovarian vasculature was observed. These findings indicate that VEGF-mediated angiogenesis is essential for corpus luteum development and endocrine function.

Ferrara's laboratory demonstrated that EG-VEGF might play a co-operative role with VEGF in the regulation of angiogenesis in the human ovary (Le Couter et al., 2001). A sequential activation of the two genes occurs in the corpus luteum formation (Ferrara et al., 2003). While VEGF is strongly expressed in early stage corpus luteum, its expression is reduced by mid-luteal phase. In contrast, EG-VEGF starts being expressed later than VEGF but persists through mid- and early-late luteal phase (Ferrara et al., 2003).

Ferrara's laboratory contributed to the description of elevations of VEGF levels in acqueous and vitreous of eyes with proliferative retinopathy (Aiello et al., 1994). In a large series where ocular fluids from 165 patients were examined, a strong correlation was found between levels of immunoreactive VEGF in the acqueous and vitreous humors and active proliferative retinopathy (Aiello et al., 1994). VEGF levels were undetectable or very low $(<0.5 \mathrm{ng} /$ $\mathrm{ml}$ ) in the eyes of patients affected by non neovascular disorders or diabetes without proliferative retinopathy. In contrast, VEGF levels were in the range of $3-10 \mathrm{ng} / \mathrm{ml}$ in the presence of active proliferative retinopathy associated with diabetes, occlusion of central retinal vein, or prematurity (Aiello et al., 1994). The VEGF levels were again very low in the eyes of patients with quiescent proliferative retinopathy, a phase of vascular regression that follows the period of active vascular proliferation in diabetic and other retinopathies (Aiello et al., 1994).
In 1993, Ferrara's laboratory reported that anti-VEGF monoclonal antibodies exerted a potent inhibitory effect on the growth of three tumor cell lines injected subcutaneously in nude mice, the G55 glioblastoma multiforme, the SK-LMS-1 leiomyosarcoma and the A673 rhabdomyosarcoma, whereas the antibody had no effects on the tumor cell in vitro, consistent with the hypothesis that the inhibition of angiogenesis is the mechanism of tumor suppression in vivo (Kim et al., 1993). The growth inhibition ranged between $70 \%$ and more than $95 \%$. These findings provided the first direct demonstration that inhibition of the action of an endogenous endothelial cell mitogen may result in suppression of tumor growth in vivo.

Subsequently, Ferrara's laboratory demonstrated that many other cell lines were inhibited in vivo by anti-VEGF monoclonal antibodies (Warren et al., 1995; Borgstrom et al., 1996, 1998, 1999; Mesiano et al., 1998). The density of blood vessels was significantly lower in sections of tumors from antibody-treated animals as compared with controls. Furthermore, neither the antibodies nor VEGF had any effects on the in vitro growth of tumor cells. Intravital videomicroscopy techniques have allowed a more direct verification of the hypothesis that anti-VEGF antibodies indeed block tumor angiogenesis (Borgstrom et al., 1996). Tumor spheroids of A673 cells were implanted in dorsal skinfold chambers inserted in nude mice. Noninvasive imaging of the vasculature revealed a nearly complete suppression of tumor angiogenesis in anti-VEGF treated animals as compared with controls. Histological analysis showed a dramatic difference in the density of CD34-positive vascular elements between the two groups. Warren et al. (1995) demonstrated that VEGF is a mediator of the in vivo growth of human colon carcinoma HM7 cells in a orthotopic nude mouse model of liver metastasis. In this murine model the expression of Flk-1 mRNA was markedly up-regulated in the vasculature associated with liver metastases. Treatment with anti-VEGF monoclonal antibodies resulted in a dramatic decrease in the number and size of metastases. Also, neither blood vessels nor Flk-1 mRNA expression could be demonstrated in such metastases.

Three different human tumor cell lines (UB7, P-MELand LS174T) were implanted in two locations in immunodeficient mice, the cranium and the dorsal skinfold (Yuan et al., 1996). Treatment with an anti-VEGF monoclonal antibody was initiated when the tumor

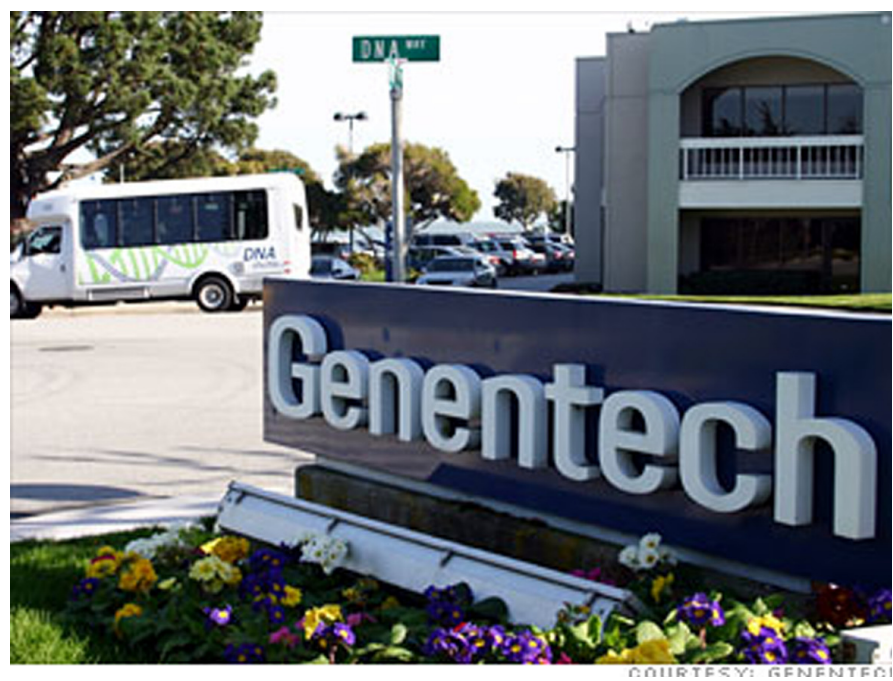

Fig. 2. Genentech headquarters in San Francisco, California. 
xenografts were already established and vascularized and resulted in time-dependent reductions in vascular permeability. These effects were accompanied by striking changes in the morphology of the vessels with dramatic reduction in diameter and tortuosity (Yuan et al., 1996).

The first antiangiogenic agent approved by the FDA was bevacizumab (Fig. 3; Avastin, Genentech Inc.), a humanized version (Presta et al., 1997) of an anti-VEGF monoclonal antibody used in early proof of concept studies (Kim et al., 1993). Like its murine counterpart, bevacizumab binds and neutralizes all human VEGF$A$ isoforms and bioactive proteolytic fragments, but not mouse or rat VEGF. Bevacizumab inhibited the growth of human tumor cell lines in nude mice, achieving a maximal inhibition at the dose of 1-2 $\mathrm{mg} / \mathrm{kg}$ twice weekly (Presta et al., 1997). The magnitude of the inhibition was inversely related to the content of stromal-derived mouse VEGF within the tumor xenograft. In tumors with high human/mouse VEGF ratio, the inhibition can exceed 90\% (Warren et al., 1995; Gerber et al., 2000).

In 1997, Genentech initiated phase I clinical trials with bevacizimab, showing that the antibody as a single agent was relatively non-toxic and that adding it to standard chemotherapy regimen did not significantly exacerbate chemotherapy-associated toxicities (Margolin et al., 2001; Gordon et al., 2001).

In 1998, several phase II studies were initiated with bevacizumab in different tumor types, either as single agent or in combination with chemotherapy. The most encouraging efficacy results were seen when bevacizumab was combined with standard first-line chemotherapy in metastatic colorectal cancer (Kabbinavar et al., 2003), and stage IIIb/IV non-small cell lung cancer (De Vore et al., 2000), and when was used as a single agent in renal cell cancer (Yang et al., 2003).

The clinical trial that resulted in FDA approval of Avastin in February 2004 was a randomized double-blind phase III study in which Avastin was administered in combination with bolus IFL (irinotecan, $5 F U$, leucovirin) chemotherapy as first-line therapy for previous untreated metastatic colorectal cancer (Hurwitz et al., 2004). Median survival was increased from 15.6 months in the bolus-IFL+placebo arm to 20.3 months in the bolus-IFL+bevacizumab arm. Similar increases were seen in progression-free survival, response rate, and duration of response. The clinical benefit of Avastin was seen

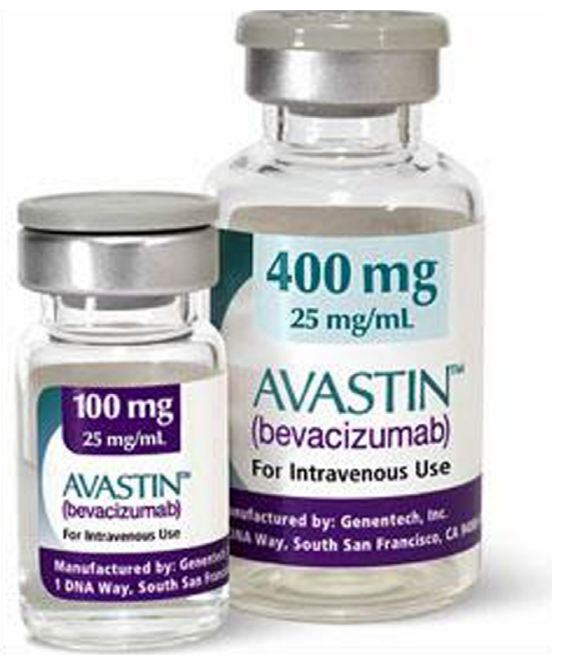

Fig. 3. Avastin is administered as an intravenous injection.
TABLE 1

\begin{tabular}{ll}
\multicolumn{2}{c}{ Awards \& Honors } \\
\hline Special Recognition ARVO/AFER & 2011 \\
Lasker DeBakey Clinical Medical Research Award & 2010 \\
Jules Gonin Lecture, Retina Research Foundation & 2010 \\
Macula Society, Michaelson Symposium Award & 2010 \\
Mortel Lecturership in Cancer Research, Penn State University & 2009 \\
Pezcoller Foundation-AACR International Award & 2009 \\
NDDO Honorary Award Lecture & 2009 \\
Macula Society, Arnall Patz Award & 2008 \\
Bruce I. Terman Memorial Lecture, Albert Einstein College of Medicine & 2008 \\
Doctor honoris causa, University of Eastern Piedmont, Novara, Italy & 2007 \\
ASCO Science of Oncology Award & 2007 \\
C. Chester Stock Award, MSKCC & 2007 \\
Society for Medicines Research Award & 2006 \\
General Motors Cancer Research Award & 2006 \\
Elected to the National Academy of Sciences, USA & 2006 \\
Passano Award & 2006 \\
Grand Prix Lefoulon-Delalande-Institut de France & 2005 \\
AACR Bruce F. Cain Memorial Award & 2005 \\
Discover Magazine Award for Medicine & 2004 \\
American-Italian Cancer Foundation Prize & 2004 \\
AlRCMO Prize for Research in Opthalmic Disorders & 2004 \\
\hline
\end{tabular}

in all subject subgroups (Hurwitz et al., 2004). Hypertension was more common in the IFL/Avastin-treated group, but was readily managed in all cases with oral antihypertensive agents (Hurwitz et al., 2004). In 2006, the FDA approved Lucentis (ranibizumab), an anti-VEGF antibody derived from the same murine antibody as Avastin, as a therapy for neovascular age-related macular degeneration.

I really appreciated the chance to interview Napoleone Ferrara who, in the course of his career, has received numerous awards and honors (see Table 1). The interview for practical reasons was conducted via electronic mail.

\section{What are your best memories of your Italian times?}

I was born on 26 July 1956 in Catania. I studied medicine at the University of Catania Medical School in the period between 1975 and 1981. I was fortunate to have the opportunity to perform some research in the Department of Pharmacology as a part of a thesis for my medical degree. My mentor, Professor Umberto Scapagnini, was a well-established investigator in the fields of neuroendocrinology and neuropharmacology. He was able to communicate a lot of excitement about research to many young people, including myself. So, I was inspired to do research during my medical school years and I developed an interest in pursuing it further. This is certainly one of my best memories of that period.

\section{What events led to your identification of VEGF and its crucial role in angiogenesis?}

I did my post-doctoral research at the University of California San Francisco (UCSF) in the Department of Obstetrics, Gynecology and Reproductive Sciences, in Doctor Richard Wiener's laboratory, which specialized in endocrinology and pituitary gland function. In the early 1980s, one of the critical questions we were asking was: which factors regulate the development of the pituitary vasculature?

During my postdoctoral stage I isolated and characterized folliculo-stellate cells, a population of non-hormone-secreting cells from the anterior pituitary (Ferrara et al., 1987). These cells had unclear function, but, intriguingly, they have close proximity with 
the perivascular spaces. To test the hypothesis that these cells play some role in the growth of the pituitary vasculature, I added their conditioned media to endothelial cells and I observed a strong mitogenic effect, indicating that folliculo-stellate cells secrete a growth factor(s) for endothelial cells - that is how my work started.

I worked on the isolation of VEGF-A in my spare time during my first six months to a year at Genentech. Once we cloned VEGF-A in 1989, the company became interested and this became more and more my full time persuit.

You discovered VEGF. What have been the most important consequences of your discovery for developmental biology and cancer?

At that time it would have been difficult to predict it, but VEGF proved to be a fundamental molecule in vascular development and in angiogenic processes in the adult. It became clear that it plays a key role in embryonic development. Also, VEGF appears important also in skeletal and reproductive angiogenesis. However, the most significant biomedical implications of VEGF concern its role as a mediator of pathological angiogenesis, such as that associated with cancer and intraocular neovascular disorders.

You have contributed to the development of Avastin. Could you
explain the importance of antiangiogenic therapy in cancer?

The long-standing hypotheses that tumor growth is angiogenesisdependent and that anti-angiogenesis may represent a therapeutic strategy for cancer generated much enthusiasm in the field. However, in the absence of defined molecules to target, it proved difficult to bring these concepts to fruition. VEGF and its receptors became major targets of cancer therapy, leading to approval of bevacizumab and other VEGF pathway inhibitors, such as small molecule tyrosine kinase inhibitors, for various malignancies. Indeed, a benefit has been observed across multiple tumor types.

In the trials that we peformed, patients treated with Avastin survived longer but they eventually succumbed to the disease. On the other hand, it is possible that in patients with less advanced or severe cancer, the therapeutic impact of Avastin would be greater. I would point out that impressive results were obtained in previously untreated metastatic colorectal cancer patients when Avastin was given in combination with chemotherapy. Moreover, Avastin prolongs survival also in patients with metastatic colorectal cancer that had been previously treated with the chemotherapy and relapsed. Avastin has just been approved in the European Union and I am delighted to know that the drug is available to patients in numerous countries, including my native country.

However, I should emphasize that although the focus of most angiogenesis researchers is on cancer, the most compelling benefits of anti-angiogenic therapy have been obtained in non-malignant disorders such as neovascular age-related macular degeneration (AMD). Lucentis (ranibizumab), a high affinity Fab fragment of Avastin, is in phase III clinical trials for wet AMD. Anti-VEGF therapy with Lucentis resulted in substantial and durable benefits, including increases in visual acuity. Other possible indications are diabetic retinopathy and retinal vein occlusion.

Systemic VEGF blockade has been associated with some significant side effects in some patients. Therefore, further understanding of the epidemiology and mechanism of such side effects will require a fuller understanding of the risk/benefit ratio before clinical trials with VEGF inhibitors can begin.
Who or what have been the greatest influences on your career?

As I mentioned, my research interests were initially in the fields of neuroendocrinology and reproductive biology. I developed these interests while working with Professor Umberto Scapagnini. During my postdoctoral fellowship in Doctor Richard Weiner's laboratory at UCSF, I became interested in angiogenesis in endocrine glands such as the pituitary. This led to my long-standing interest in angiogenesis.

\section{Of your all research, what do you consider as the most im- portant?}

The fact that approximately 500,000 patients have been treated with bevacizumab and many have benefited from the treatment, is even more important to me that basic science discoveries. Likewise, the fact that ranibizumab therapy reduces vision loss in patients with age-related macular degeneration is a great source of inspiration.

Launched in Europe in 2005 under the name Avastin, the new drug is distributed by Swiss-based pharmaceutical company Roche. The drug is currently Genentech's top-selling product, generating 4.8 billion dollars in global annual sales. Currently, more than 450 clinical trials are underway worldwide to test the effect of this drug on 30 different types of tumors.

\section{References}

AIELLO L.P., AVERY R., ARRIGG R., KEYT B., JAMPEL H., SHAH S., PASQUALE L., THIEME H., IWAMOTO M., PARK J.E., NGUYEN H., AIELLO L.M., FERRARA N., and KING G.L. (1994). Vascular endothelial growth factor in ocular fluid of patients with diabetic retinopathy and other retinal disorders. New Engl. J. Med., 331: 1480-1487.

BORGSTROM P., HILLANK.J., SRIRAMARAO P., and FERRARAN. (1996). Complete inhibition of angiogenesis and growth of microtumors by anti-vascular endothelial growth factor neutralizing antibody: novel concept of angiostatic therapy from intravital videomicroscopy. Cancer Res. 56: 4032-4039.

BORGSTROM P., BOURDON M.A., HILLAN K.J., SRIRAMARAO P., and FERRARA N. (1998). Neutralizing anti-vascular endothelial growth factor antibody completely inhibits angiogenesis and growth of human prostate carcinoma microtumors in vivo. Prostate, 35: 1-10.

BORGSTROM P., GOLD D.P., HILLAN K.J., and FERRARA N. (1999). Importance of VEGF for breast cancer angiogenesis in vivo: implications from intravital microscopy of combination treatments with an anti-VEGF neutralizing antibody and doxorubicin. Anticancer Res. 19: 4203-4214.

CARMELIET P., FERREIRA V., BREIER G., POLLEFEYET S., KIECHENS L., GERTSENSTEIN M., FAHRIG M., VANDENHOECKA., HARPALK., EBERHARDT C., DECLERCQ C., PAWLING J., MOONS L., COLLEN D., RISAU W., and NAGY A. (1996). Abnormal blood vessel development and lethality in embryos lacking a single VEGF allele. Nature, 380: 435-439.

CLEAVER, O., and MELTON, D.A. (2003). Endothelial signalling during development. Nature Med. 9: 661-668.

DE VRIES C., ESCOBEDO J.A., UENO H., HOUCKK., FERRARAN., and WILLIAMS L.T. (1992). The fms-like tyrosine kinase, a receptor for vascular endothelial growth factor. Science 255: 989-991.

ESSER, S., WOLBURG, K., WOLBURG, H., BREIER, R.G., KURZCHALIANT T., and RISAU, W. (1998). Vascular endothelial growth factor induces endothelial fenestrations in vitro. J. Cell. Biol. 140: 947-859.

FERRARA N., FUJII D.K., GOLDSMITH P.C., WIDDICOMBE J.H., and WEINER R.I. (1987). Transport epithelial characteristics of cultured bovine pituitary follicular cells. Am. J. Physiol. 252: E304-E312.

FERRARA, N., and HENZEL, W.J. (1989). Pituitary follicular cells secrete a novel heparin-binding growth factor specific for vascular endothelial cells. Biochem. Biophys. Res. Commun. 161: 851-858.

FERRARA N., CARVER-MOORE K., CHEN H., DOWD M., LU L., O'SHEA K.S., POWELL BRAXTON L., HILLAN K.J., and MOORE M.W. (1996). Heterozygous embryonic lethality induced by targeted inactivation of the VEGF gene. Nature, 
380: 439-442

FERRARA N., CHEN H., DAVIS SMYTH T., GERBER H.P., NGUYEN T.N., PEERS D., CHISHOLM V., HILLAN K.J., and SCHWALLR.H. (1998). Vascular endothelial growth factor is essential for corpus luteum angiogenesis. Nature Med. 4:336-340.

FERRARA N., FRANTZ G., LE COUTER J., DILLARD-TELM L., PHAM T., DRAKSHARAPU A., GIORDANO T., and PEALE F. (2003). Differential expression of the angiogenic factor genes VEGF and EG-VEGF in normal and polycistic human ovaries. Am. J. Pathol. 162: 1881-1893.

GERBER H.P., CONDORELLI F., PARK J., and FERRARA N. (1997). Differential transcriptional regulation of the two VEGF receptor genes. Flt-1, but not Flk-1/ KDR is up-regulated by hypoxia. J. Biol. Chem. 272: 23659-23667.

GERBER H.P., VU T.H., RYAN A.M., KOWALSKI J., WERB Z., and FERRARA N. (1999). VEGF couples hypertrophic cartilage remodeling, ossification and angiogenesis during endochondral bone formation. Nature Med. 5: 623-628.

GERBER H.P., KOWALSKI J., SHERMAN D., EBERHARD D.A., and FERRARA N. (2000). Complete inhibition of rhabdomyosarcoma xenograft growth and neovascularization requires blockade of both tumor and host vascular endothelial growth factor. Cancer Res. 60: 6253-6258

GORDON M.S., MARGOLIN K., TALPAZ M., SLEDGE G.W. JR, HOLMGREN E., BENJAMIN R., STALTER S., SHAK S., and ADELMAN D. (2001). Phase I safety and pharmacokinetic study of recombinant human anti-vascular endothelial growth factor in patients with advanced cancer. J. Clin. Oncol. 19: 843-850.

HURWITZ, H., FEHRENBACHER, L., NOVOTNY, W., CARTWRIGHT, T., HAINSWORTH, H., HELM, W., BERLIN, J., GRIFFINGS, S., HOLMGREN, R., FERRARA, N., ROGERS, B., ROSS, R., BARON, A., and KABBINAVAR, F. (2004). Bevacizumab plus irinotecan, fluorouracil, and leucovarin for metastatic colorectal cancer. New Eng. J. Med. 350: 2335-2342.

HOUCK, K.A., FERRARA, N., WINER, J., CACHIANES, G., LI, B., and LEUNG, D.W. (1991). The vascular endothelial growth factor family: identification of a fourth molecular species and characterization of alternative splicing RNA. Mol. Endocrinol. 5: 1806-1814.

HOUCK, K.A., LEUNG, D.W., ROWLAND, A.M., WINER, J., and FERRARA, N. (1992). Dual regulation of vascular endothelial growth factor bioavailability by genetic and proteolytic mechanisms. J. Biol. Chem. 267: 26031-26037.

HURWITZH., FEHRENBACHERL., NOVOTNYW., CARTWRIGHTT., HAINSWORTH H., HELM W., BERLIN J., GRIFFINGS S., HOLMGREN R., FERRARA N., ROGERS B., ROSS R., BARON A., and KABBINAVAR F. (2004). Bevacizumab plus irinotecan, fluorouracil, and leucovarin for metastatic colorectal cancer. New Engl. J. Med. 350: 2335-2342.

KABBINAVAR F., HURWITZ H.I., FEHRENBACHER L., MEROPOL N.J., NPVOTNY W.F., LIEBERMAN G., GRIFFING S., and BERGSLAND E. (2003). Phase II, randomized trial comparing bevacizumab plus fluorouracil (FU)/leucovorin (LV) with FU/LV alone in patients with metastatic colorectal cancer. J. Clin. Oncol. 21:60-65.
KIM, K.J., LI, B.; WINER, J., ARMANINI, M., GILLET, N., PHILLIPS. H.S., and FERRARA, N. (1993). Inhibition of vascular endothelial growth factor-induced angiogenesis suppresses tumor growth in vivo. Nature 362: 841-844.

LAMMERT E., GU G., MC LAUGHLIN M., BROWN D., BREKKEN R., MURTAUGH L.C., GERBER H.P., FERRARA N., and MELTON D.A. (2003). Role of VEGF-A in vascularization of pancreatic islets. Curr. Biol. 13: 1070-1074.

LE COUTER J., KOWALSKI J., FOSTER J., HASS P., ZHANG Z., DILLARD-TELM L., FRANTS G., RANGELL L., DEGUZMAN L., KELLER G.A., PEALE F., GURNEY A., HILLAN K.J., and FERRARAN. (2001). Identification of an angiogenic mitogen selective for endocrine gland endothelium. Nature, 412: 877-884

LE COUTER J., LIN R., and FERRARA N. (2002). Endocrine gland-derived VEGF and the emerging hypothesis of organ-specific regulation of angiogenesis. Nature Med. 8: 913-917

LEUNG, D.W., CACHIANES, G., KUANG, W.J., GOEDDEL, D.V., and FERRARA, N. (1989). Vascular endothelial growth factor is a secreted angiogenesis mitogen. Science 246: 1306-1309.

MARGOLIN K., GORDON M.S., HOLMGREN E., GAUDREAULT J., NOVOTNY W. FYFE G., ADELMAN D., STALTER S., and BREED J. (2001). Phase lb trial of intravenous recombinant humanized monoclonal antibody to vascular endothelia growth factor in combination with chemotherapy in patients with advanced cancer: pharmacologic and long-term safety data. J. Clin. Oncol. 19, 851-856.

MESIANO S., FERRARA N., and JAFFE R.B. (1998). Role of vascular endothelial growth factor in ovarian cancer: inhibition of ascite formation by immunoneutralization. Am. J. Pathol. 153, 1249-1256.

PARK J.E., CHEN H.H., WINER J., HOUCK K.A., and FERRARAN. (1994). Placenta growth factor. Potentiation of vascular endothelial growth factor bioactivity, in vitro and in vivo, and high affinity binding to Flt-1 but not to Flk-1/KDR. J. Biol. Chem. 269, 25646-25654

PRESTA, L.G., CHEN, H., O'CONNOR, S.J., CHISHOLM, V., MENG, Y.G., KRUMMEN, L., WINKLER, M., and FERRARA, N. (1997). Humanization of anti-vascular endothelial growth factor monoclonal antibody for the therapy of solid tumors and other disorders. Cancer Res. 57: 4593-4599.

WARREN R.S., YUANH., MATLIM.R., GILLETTN.A., and FERRARAN. (1995). Regulation by vascular endothelial growth factor of human colon cancer tumorigenesis in a mouse model of experimental liver metastasis. J. Clin. Invest. 95, 1789-1797.

YANG J.C., HAWORTH L., SHERRY R.M., HWU P., SCHWARTZENTRUBER D.J. TAPALIAN S.L., STEINBERG S.M., CHEN H.X., and ROSENBERG S.A. (2003). A randomized trial of bevacizumab, an anti-VEGF antibody, for metastatic renal cancer. New Engl. J. Med. 349, 427-434.

YUAN F., CHEN Y., DELLIAN M., SAFABAKHSH N., FERRARA N., and JAIN R.K. (1996). Time-dependent vascular regression and permeability changes in established xenografts induced by an anti-vascular endothelial growth factor/vascular permeability factor antibody. Proc. Natl. Acad. Sci. USA 93: 14765-14770. 


\section{Further Related Reading, published previously in the Int. J. Dev. Biol.}

Insulin-like growth factor-2 regulates early neural and cardiovascular system development in zebrafish embryos Lori Hartnett, Catherine Glynn, Catherine M. Nolan, Maura Grealy and Lucy Byrnes Int. J. Dev. Biol. (2010) 54: 573-583

The seminal work of Werner Risau in the study of the development of the vascular system Domenico Ribatti

Int. J. Dev. Biol. (2010) 54: 567-572

Estrogen regulation of placental angiogenesis and fetal ovarian development during primate pregnancy Eugene D. Albrecht and Gerald J. Pepe Int. J. Dev. Biol. (2010) 54: 397-407

\section{Uteroplacental vascular development and placental function: an update} Lawrence P. Reynolds, Pawel P. Borowicz, Joel S. Caton, Kimberly A. Vonnahme, Justin S. Luther, David S. Buchanan, Shireen A. Hafez, Anna T. Grazul-Bilska and Dale A. Redmer

Int. J. Dev. Biol. (2010) 54: 355-365

Critical growth factors and signalling pathways controlling human trophoblast invasion Martin Knöfler

Int. J. Dev. Biol. (2010) 54: 269-280

Over-expression of thymosin beta4 promotes abnormal tooth development and stimulation of hair growth Hee-Jae Cha, Deborah Philp, Soo-Hyun Lee, Hye-Sung Moon, Hynda K. Kleinman and Takashi Nakamura Int. J. Dev. Biol. (2010) 54: 135-140

The contribution of Roberto Montesano to the study of interactions between epithelial sheets and the surrounding extracellular matrix

Domenico Ribatti

Int. J. Dev. Biol. (2010) 54: 1-6

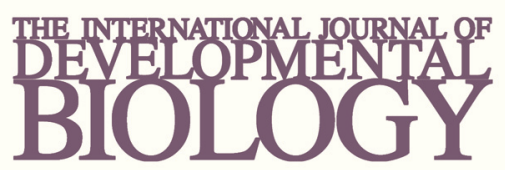

Volume 54 Nos. 6/7

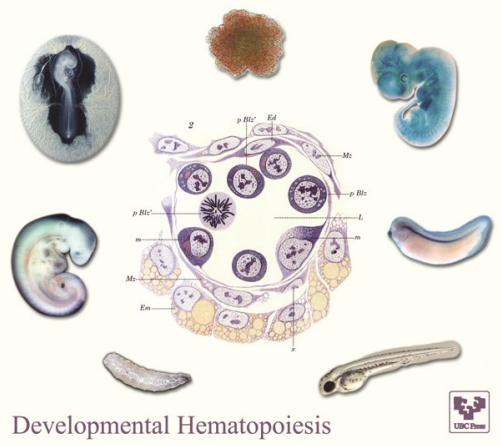

Impact Factor $(2010)=2.86$

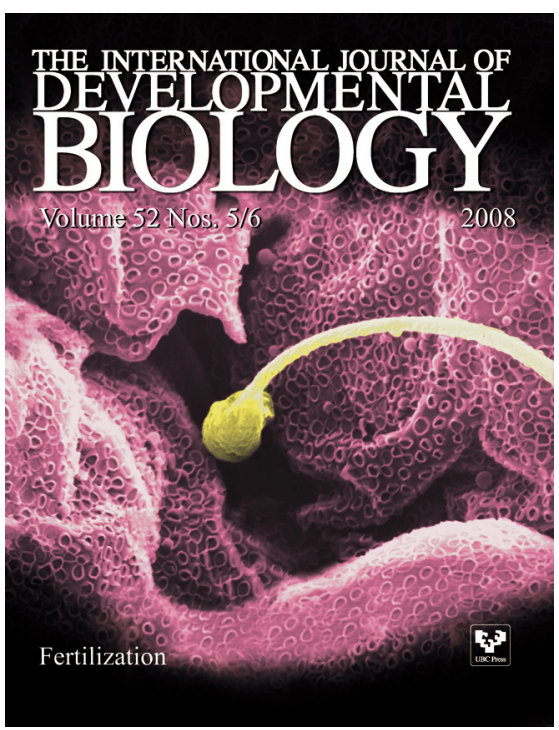

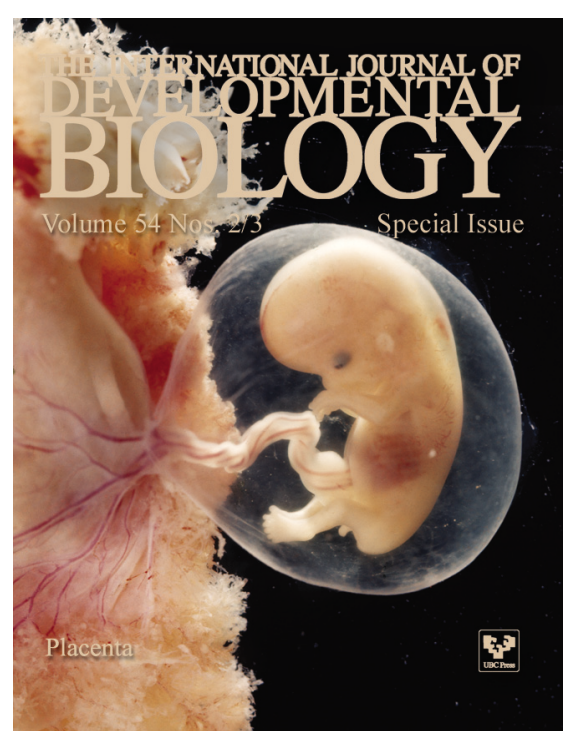

